University of Nebraska - Lincoln

DigitalCommons@University of Nebraska - Lincoln

Sociology Department, Faculty Publications

Sociology, Department of

7-2011

\title{
Infertility treatment and fertility-specific distress: A longitudinal analysis of a population-based sample of U.S. women
}

Arthur L. Greil

Alfred University, fgreil@alfred.edu

Julia McQuillan

University of Nebraska-Lincoln, jmcquillan2@Unl.edu

Michele Lowry

Alfred University, MHL1@alfred.edu

Karina M. Shreffler

Oklahoma State University, karina.shreffler@okstate.edu

Follow this and additional works at: https://digitalcommons.unl.edu/sociologyfacpub

Part of the Sociology Commons

Greil, Arthur L.; McQuillan, Julia; Lowry, Michele; and Shreffler, Karina M., "Infertility treatment and fertilityspecific distress: A longitudinal analysis of a population-based sample of U.S. women" (2011). Sociology Department, Faculty Publications. 147.

https://digitalcommons.unl.edu/sociologyfacpub/147

This Article is brought to you for free and open access by the Sociology, Department of at DigitalCommons@University of Nebraska - Lincoln. It has been accepted for inclusion in Sociology Department, Faculty Publications by an authorized administrator of DigitalCommons@University of Nebraska - Lincoln. 
Published in Social Science \& Medicine 73:1 (July 2011), pp. 87-94; doi: 10.1016/j.socscimed.2011.04.023

Copyright (C) 2011 Elsevier Ltd. Used by permission. http:/ / www.elsevier.com/locate/socscimed

Published online May 20, 2011.

\title{
Infertility treatment and fertility-specific distress: A longitudinal analysis of a population-based sample of U.S. women
}

\author{
Arthur L. Greil, ${ }^{1}$ Julia McQuillan, ${ }^{2}$ Michele Lowry,, and Karina M. Shreffler ${ }^{3}$ \\ 1. Division of Social Sciences, Alfred University, Alfred, NY \\ 2. University of Nebraska-Lincoln \\ 3. Oklahoma State University \\ Corresponding author - A. L. Greil, tel 607 871-2885, fax 607 871-2085, email fgreil@alfred.edu
}

\begin{abstract}
Because research on infertile women usually uses clinic-based samples of treatment seekers, it is difficult to sort out to what extent distress is the result of the condition of infertility itself and to what extent it is a consequence of the experience of infertility treatment. We use the National Survey of Fertility Barriers, a two-wave national probability sample of U.S. women, to disentangle the effects of infertility and infertility treatment on fertilityspecific distress. Using a series of ANOVAs, we examine 266 infertile women who experienced infertility both at Wave 1 and at Wave 2, three years later. We compare eight groups of infertile women based on whether or not they have received treatment and on whether or not they have had a live birth. At Wave 1, infertile women who did not receive treatment and who had no live birth reported lower distress levels than women who received treatment at Wave 1 only, regardless of whether their infertility episode was followed by a live birth. At Wave 2, women who received no treatment have significantly lower fertility-specific distress than women who were treated at Wave 1 or at Waves 1 and 2, regardless of whether there was a subsequent live birth. Furthermore, fertility-specific distress did not increase over time among infertile women who did not receive treatment. The increase infertility-specific distress was significantly higher for women who received treatment at Wave 2 that was not followed by a live birth than for women who received no treatment or for women who received treatment at Wave 1 only. These patterns suggest that infertility treatment is associated with levels of distress over and above those associated with the state of being infertile in and of itself.
\end{abstract}

Keywords: infertility, infertility treatment, fertility-specific distress, longitudinal women, USA

\section{Introduction}

Research on infertile women describes the feelings of distress, loss of control, social isolation, and sense of stigma that women and couples experience as they try unsuccessfully to achieve pregnancy (Becker, 2000; Greil, 1997; Greil et al., 2010). Wirtberg, Moller, Hogström, Tronstad, and Lalos (2007) find that the emotional consequences of infertility such as lower self-esteem and feelings of isolation persist even 20 years after discontinuing treatment. Prior research on the relationship between infertility and distress, however, has been limited due to several methodological shortcomings. First, most studies on the psychosocial consequences of infertility use clinic-based samples of treatment seekers, thus ignoring the experiences of those who do not seek treatment (Greil, 1997; Greil et al., 2010) and making it difficult to sort out to what extent distress is the result of the condition of infertility itself and to what extent it is a consequence of the experience of infertility treatment. A second shortcoming of many studies is that they employ crosssectional, rather than longitudinal designs, thus preventing an understanding of the causal relationship between treatment and distress (Henning \& Strauss, 2002). How are we to know, for example, whether a correlation between treatment seeking and distress among infertile women means that the treatment process itself causes distress or whether it means that more distressed women are more likely to seek treatment? A third reason for concern about findings concerning the psychological sequelae of infertility is that measures designed to assess psychopathology may not be sufficiently sensitive or specific to the problems of the infertile to adequately reflect the experience of infertility (Schmidt, 2009). In this study, we use panel data from a two-wave national probability sample of 4787 U.S. women to begin to disentangle the effects of infertility and infertility treatment on fertility-specific distress. 


\section{Literature review}

According to commonly accepted medical criteria, women are categorized as infertile if they experience a year of regular, unprotected intercourse without conception (Zegers-Hochschild et al., 2009). According to the National Survey of Family Growth, $15 \%$ of U.S. women reported "impaired fecundity" in 2002 (Chandra, Martinez, Mosher, Abma, \& Jones, 2005), but lifetime prevalence rates are considerably higher. The National Survey of Fertility Barriers data set employed in this study reveals that $51.8 \%$ of women aged 25 to 45 reported an episode of infertility at some point in their lives.

\section{Infertility and psychological distress}

There is little evidence of psychopathology among infertility patients (Edelmann and Connolly, 1998; Eugster and Vingerhoets, 1999; Yli-Kuha et al., 2010), although there may be a subgroup that needs psychological help (Wischmann, Stammer, Scherg, Gerhard, \& Verres, 2001). Infertile women are not necessarily more likely to exhibit psychopathology than noninfertile women, but they do seem more likely to experience higher levels of distress than comparison groups (Fido and Zahid, 2004; Matsubayashi et al., 2001; Monga et al., 2004). In a rare study using a probability-based sample, King (2003) found that, compared to fecund women, subfecund women participating in the National Survey of Family Growth have more symptoms of anxiety, as measured by the Generalized Anxiety Disorder Scale. Wischmann et al. (2001) found that women in a German clinic reported slightly higher stress than norms and also scored lower than norms on a number of subscales of life satisfaction. Infertile women also have higher distress scores on the Patient Health Questionnaire than do other women in family practice clinics (Jordan \& Ferguson, 2006). A few studies, however, have produced anomalous results. For example, several studies (Holter et al., 2006; Klock and Greenfeld, 2000; Verhaak et al., 2005) have found that women who have undergone in vitro fertilization (IVF) do not differ significantly from norms on general distress. This appears to be true even if treatment did not result in a live birth (Johansson et al., 2009).

There are important limitations to studying distress among women with infertility using cross-sectional studies comparing infertile women to norms or to a control group. First, crosssectional data do not permit clear causal inferences. Furthermore, it is not clear how to construct a proper control group with which to compare infertile women. Researchers have compared the infertile to people seeking elective sterilization (Monga et al., 2004), pregnant women (Fido and Zahid, 2004; Matsubayashi et al., 2001), parents (Johansson et al., 2009), women in the same family practice as the infertile (Jordan \& Ferguson, 2006), and couples who conceived without intervention (Oddens, den Tonkelaar, \& Nieuwenhuyse, 1999), but none of these groups is ideal. Any cross-sectional study using a comparison group, however, fails to address a crucial question (Greil, 1997): does experiencing infertility meaningfully increase distress? To answer this question unambiguously, it is necessary to compare distress levels before and after experiencing infertility and/or treatment for infertility.

Some researchers have argued that standardized measures are not sufficiently sensitive or specific to the problems of infertility to adequately reflect the experience of infertility (Berg, 1994; Greil et al., 2010; Schmidt, 2009). General measures of distress are not designed to assess strains specifically related to infertility. The fact that specific measures of infertility stress tend to correlate strongly with standardized measures argues for the acceptability of specific infertility measures (Abbey et al., 1991;
Sabatelli et al., 1988; Ulbrich et al., 1990). A disadvantage of fertility-specific measures is that they do not permit comparison with control groups or population norms. These measures are more useful when looking for differences in distress among the infertile and in longitudinal designs. A number of measures of fertility-specific distress have been developed (See especially Abbey et al., 1991; Hjelmstedt et al., 2004; Jacob et al., 2007; Newton et al., 1999; Schmidt, 2006), but none of these measures has achieved the status of a standard measure. Measures which have been used or adapted by other researchers include those developed by Abbey et al. (1991), Hjelmstedt et al. (1999), Newton et al. (1999), and Schmidt (2006).

\section{Treatment and psychological distress}

Clinic-based studies of treatment seekers still prevail in research on the consequences of infertility (Henning \& Strauss, 2002). The focus on people receiving treatment makes it difficult to generalize to those who do not seek treatment (Greil, 1997; Greil et al., 2010). In the United States, for example, fewer than $50 \%$ of infertile women seek treatment (Greil and McQuillan, 2004; Stephen and Chandra, 2000); clinic-based studies therefore provide no information about half of the female infertile population (Berg and Wilson, 1990; Greil et al., 2010; Wright et al., 1991). Without a non-clinic comparison group, it is difficult to untangle the effects of infertility from the effects of infertility treatment on psychological outcomes. Evidence suggests that the characterization of infertile women as highly distressed and totally immersed in the process of trying to become pregnant applies primarily to treatment seekers (Greil and McQuillan, 2004; Jacob et al., 2007; White et al., 2006).

In recent years, there have been some important studies using non-clinic based samples that have looked at issues related to treatment and distress among infertile women. King (2003) used the National Survey of Family Growth, a nationally representative sample that included infertility status data for women in the United States to assess whether treatment seekers and non-treatment seekers are more likely to meet the criteria for anxiety and concluded that the effects of infertility on Generalized Anxiety Disorder are not moderated by treatment. She was limited, however, by the nature of the questions assessing psychosocial characteristics in the data set. Malin, Hemminki, Raikkonen, Sihvo, and Perala (2001) made use of a Finnish probability sample to determine degree of satisfaction with treatment. Redshaw, Hockley, and Davidson (2007) used a nationally representative sample of women who had recently given birth in the United Kingdom to assess reactions to infertility treatment. This data set is limited to people who eventually had a child.

Evidence exists to suggest that infertile women who seek treatment find the treatment experience highly stressful. Patients report feeling that they have little control over treatment and that they are not being treated like people (Redshaw et al., 2007). Several studies have shown that patients are intimidated by the language of biomedicine and by the technical aspects of infertility treatment, especially in situations where language barriers exist (Becker et al., 2005; Culley et al., 2006; Wingert et al., 2005). The infertility treatment experience has been described as a situation that engulfs patients and dominates their daily routine (Daniluk, 2001; Redshaw et al., 2007).

In a study of Dutch women, Van Balen and Verdurmen (1999) found that medical anxiety was significantly associated with the choice of options for dealing with infertility, including medical treatment, adoption, foster care, alternative medicine, and other life goals. Chiba et al. (1997) compared women who had been in treatment for varying periods of time and 
found that the long-term group scored considerably higher on a measure of depression than the short-term group. Verhaak, Smeenk, Evers, Kremer, Kraaimaat, and Braat (2007) reported that stopping treatment leads to reduced depression and anxiety among IVF women even if they do not conceive. There is research on the psychological predictors of treatment persistence among infertile couples (Strauss, Hepp, Staeding, \& Mettler, 1998), but we know of no studies designed to compare treatment seekers to non-treatment-seekers.

\section{Longitudinal analyses}

Cross-sectional analysis is still the most common design in studies of the social and psychological consequences of infertility. As noted above, this makes it impossible to sort out cause and effect. Until recently, longitudinal studies employed a fairly short (less than a year) time frame (Anderson et al., 2003; Hjelmstedt et al., 2004; Holter et al., 2006; Mindes et al., 2003; Verhaak, Smeenk, Evers et al., 2007a). In the past several years, however, longitudinal studies with a followup three to five years after the initial data collection have begun to appear (Peterson et al., 2009; Pinborg et al., 2009; Rosholm et al., 2010; Verhaak, Smeenk, Nahuis et al., 2007b). For example, the Copenhagen Multi-Center Psychosocial Infertility study (Boivin and Schmidt, 2005; Peronace et al., 2007; Schmidt, 2006; Schmidt et al., 2005) measured 1081 Danish women and 1081 men at their initial visit to an infertility clinic with follow-ups after one and five years. There are also several cross-sectional studies that have looked at distress among infertile women and men three to five years following treatment (Johansson et al., 2009; Johansson et al., 2010; Volgsten et al., 2010). Although some longitudinal studies show that distress increases as treatment persists, others find no relationship between duration of treatment and distress. Edelmann and Connolly (2000) found that distress did not increase after seven months of treatment, and Anderson et al. (2003) found no differences for men or women on the Hospital Anxiety and Depression Scale or infertility-specific distress from just prior to initial visit to six months later. Nasseri (2000), however, found that psychological distress and social withdrawal are higher after treatment than during initial consultation. None of these studies was designed to allow for comparisons between those who received treatment and those who did not.

It seems reasonable to expect that not conceiving a child from treatment would be more stressful than treatment followed by conceiving or bearing a child. A qualitative study found that both women and men in couples who had undergone IVF treatment without conception were still expressing feelings of grief three years later (Volgsten et al., 2010). Two retrospective cross-sectional studies (Johansson et al., 2010; McQuillan et al., 2003) found long-term negative consequences of infertility only among women who remained involuntarily childless. Mindes et al. (2003) administered coping, depression, and self-esteem scales at two points in time 6-12 months apart and found that women who remained infertile reported more distress than those who became pregnant. Verhaak et al. (2001) observed that IVF women who do not conceive show increased levels of anxiety and depression during treatment and that both women who gave birth and those who did not eventually showed a decline in depression and anxiety over time. Peterson et al. (2009) found that personal and marital distress declined among both women and men in the five years following unsuccessful IVF treatment. Somewhat surprisingly, Bevilacqua, Barad, Youchah, and Witt (2000) reported that women who conceive following treatment have higher trait anxiety than women who do not. Any thorough study of the effects of in- fertility, treatment, and distress will need to take into account whether or not treatment resulted in a pregnancy.

\section{Statement of the problem}

The question of the extent to which distress among infertile women is due to the condition of infertility itself or to infertility treatment remains unresolved. This question can be best answered by comparing infertile women who do not receive treatment to those who do receive treatment. Levels of distress in both groups of women also need to be compared at two points in time. Additionally, it is necessary to take into account whether infertile women who received treatment reported a live birth subsequent to treatment. If the distress is solely due to having had an infertility episode, then fertilityspecific distress should not vary much by treatment group. On the other hand, if infertility treatment is distressing, then infertile women who have received treatment should report more distress than infertile women who did not receive treatment. We therefore evaluate the following hypotheses:

Hypothesis 1 - Women who received treatment at Wave 1 or Wave 2 should report higher levels of fertility-specific distress than woman with infertility who have not received treatment.

Hypothesis 2 - Women who report having received treatment at both Wave 1 and Wave 2 should report higher levels of fertility-specific distress than women who have received treatment at Wave 2 only.

Hypothesis 3 - Women with live births following infertility will report lower levels of distress than women who have not had a live birth.

\section{Methods}

\section{Respondents}

The National Survey of Fertility Barriers (NSFB) conducted telephone interviews with a probability-based sample of 4787 U.S women aged 25 to 45 during the years 2004-2007 (Wave 1) with follow-up interviews with all women who could be reached three years after the initial interview (Wave 2). Interviews were also conducted at Wave 1 with about $20 \%$ of partners of the main respondents to permit analyses of couple-level data, but the partner interviews are not included in this analysis. This Random Digit Dialing sample consists of a nationally representative sample, plus an over-sample of Census central office codes with a high minority population to ensure sufficient numbers of women for subgroup analyses. Our sample design included a pre-notification letter with a $\$ 1$ or $\$ 2$ cash incentive for all telephone numbers with address matches. The incentive was changed from $\$ 2$ to $\$ 1$ following an experimental comparison built into a random sample segment that found little difference in response rate between the two amounts. Interviewing was conducted by the Survey Research Center at the Pennsylvania State University and the Bureau of Sociological Research at the University of Nebraska-Lincoln. Internal Review Boards at both universities approved the study. The same interviewer training material and interviewer guides were used at both sites. Methodological information, including the methodology report, introductory letters, interview schedules, interviewer guides, data imputation procedures, and a detailed description of the planned missing design can be accessed at: http://sodapop.pop.psu.edu/codebooks/nsfb/wave1/. The public-access data files can be accessed at: http:// sodapop.pop.psu.edu/ data-collections/nsfb . 
Because this was designed as a two-wave study, it was necessary to include sufficient numbers of women who would encounter a fertility barrier between waves of data collection. Therefore, screening questions were used to identify women who had an infertility episode, who had never given birth, who had miscarried in the past, and/or who would like to have a baby in the future, and only selected $10 \%$ of women who reported having completed child bearing or had a low likelihood of a fertility problem (the comparison group). Interviews were designed to take approximately $35 \mathrm{~min}$ and included detailed reproductive histories, demographic measures, and attitudinal measures, including the fertility-specific distress measure employed in this study. A "planned missing" design was used to provide a way to incorporate more indicators of key concepts while minimizing respondent burden and keeping the interview relatively short. The estimated response rate for the sample is $53.0 \%$ for the screener, which is typical for RDD telephone surveys conducted in recent years (McCarty, House, Harman, \& Richards, 2006). Extensive comparisons with Census data indicate our weighted sample is representative of women age 25-45 in the United States.

An attempt was made to re-interview a subsample of main respondents and all partners three years after their original interview. Wave 2 has yielded 2136 main respondent interviews. This number is $58 \%$ of those sought. Almost all of the attrition between waves of data collection reflects an inability to contact respondents; only $6 \%$ of those we were able to talk to on the phone refused to participate. An analysis using a series of logistic regression models with response to Wave 2 as the outcome makes it clear that the non-response to Wave 2 was driven primarily by variables reflecting mobility and the amount of identifying information we had on the respondent at Wave 1. Contact rates were lower for younger women, unmarried women, women of lower socio-economic status, and minority women. The critical issue related to bias is whether the attrition affected the central variables related to child bearing, infertility, and health outcomes. Logistic regression analysis suggests that there is little association between attrition and variables central to the questions of this study.

The sample for this analysis includes all women $(N=266)$ who were interviewed during both Waves 1 and 2 and who reported infertility both at Wave 1 and at Wave 2 three years after the initial interview. Women were considered infertile at Wave 1 if they responded "yes" to either of the following questions: "Was there ever a time when you were trying to get pregnant but did not conceive within 12 months?" and "Was there ever a time when you regularly had sex without birth control for a year or more without getting pregnant?" Women were considered infertile at Wave 2 they responded "yes" to either of the following questions: "Since we spoke with you last in [Month, year], was there ever a time when you were trying to get pregnant but did not conceive within 12 months?" and "Since we spoke with you last in [Month, year], was there ever a time when you regularly had sex without birth control for a year or more without getting pregnant?" Thus, our sample includes only women who reported infertility both at Wave 1 and Wave 2. Therefore, changes in distress levels are unlikely to be attributable to changes in fecundity between waves. Infertility is better understood as a couple phenomenon rather than a problem for women alone. Unfortunately, we have partner data for only 122 of the 266 women in the sample; we therefore limited this analysis to the main (female) respondents in order to avoid problems with statistical power.

\section{Measures}

Infertility treatment was assessed through a series of questions about help-seeking, tests, and treatments. For this analysis, we treat treatment as a dichotomous variable with " 1 " indicating that a woman has received infertility tests and a " 0 " indicating that she has not received infertility tests. Treatment outcome and live birth were constructed from birth and pregnancy histories. We noted whether a woman had a live birth after an infertility episode for which she received treatment, but we were not able to ascertain whether the live birth resulted from the treatment received. A woman who did not receive treatment was considered to have had a live birth if she reported a live birth at any time after her first infertility episode. Based on responses to questions about treatment and live births, we classified women into eight mutually exclusive groups:

1. Infertile women who have not received treatment and have not had a live birth subsequent to infertility.

2. Infertile women who have not received treatment and have had a live birth subsequent to infertility.

3. Infertile women who received treatment at Wave 1 and have not had a live birth subsequent to infertility.

4. Infertile women who received treatment at Wave 1 and have had a live birth subsequent to infertility.

5. Infertile women who received treatment at Wave 2 and have not had a live birth subsequent to infertility.

6. Infertile women who received treatment at Wave 2 and have had a live birth subsequent to infertility.

7. Infertile women who received treatment at Wave 1 and Wave 2 and have not had a live birth subsequent to infertility.

8. Infertile women who received treatment at Wave 1 and Wave 2 and have had a live birth subsequent to infertility.

Table 1 provides a succinct summary of these eight groups.

The dependent variable in this study is fertility-specific distress. As noted above, there is no established instrument in general use for assessing emotional responses to infertility. In addition, it was important for the purposes of the larger study to phrase questions using language general enough to apply to other fertility barriers in addition to infertility (such as pregnancy loss and situational fertility barriers). Thus, a 6-item scale based on questions that draw on Hjelmsted and colleagues' (1999) Infertility Reaction Scale, qualitative research on infertile couples (e.g. Greil, 1991), and the clinical experi-

Table I. Description of treatment/live birth groups.

\begin{tabular}{|c|c|c|c|c|c|}
\hline No. & Group & $\mathrm{N}$ & $\begin{array}{l}\text { Treatment } \\
\text { atWI }\end{array}$ & $\begin{array}{l}\text { Treatment } \\
\text { atW2 }\end{array}$ & $\begin{array}{l}\text { Live birth } \\
\text { after infertility }\end{array}$ \\
\hline I & No treatment \& no live birth & 44 & No & No & No \\
\hline 2 & No treatment \& live birth & 69 & No & No & Yes \\
\hline 3 & Treatment wl only \&no live birth & 62 & Yes & No & No \\
\hline 4 & Treatment wl only \& live birth & 31 & Yes & No & Yes \\
\hline 5 & Treatment w2 only \& no live birth & 24 & No & Yes & No \\
\hline 6 & Treatment w 2 only \& live birth & 5 & No & Yes & Yes \\
\hline 7 & Treatment wlw2 \& no live birth & 19 & Yes & Yes & No \\
\hline 8 & Treatment wlw2 \& live birth & 12 & Yes & Yes & Yes \\
\hline
\end{tabular}


Table 2. Fertility-specific distress by treatment group in a sample of 266 infertile women.

\begin{tabular}{|c|c|c|c|c|c|c|c|c|c|c|c|c|}
\hline & \multicolumn{12}{|c|}{ Fertility Specific Distress } \\
\hline & \multicolumn{4}{|c|}{ Wave I } & \multicolumn{4}{|c|}{ Wave 2} & \multicolumn{3}{|c|}{ FSD Change } & \\
\hline & Mean & SD & $\mathrm{N}$ & & Mean & SD & $\mathrm{N}$ & & Mean & SD & $\mathrm{N}$ & \\
\hline No treatment \& no live birth & 0.23 & 0.34 & 44 & $\mathrm{a}$ & 0.22 & 0.30 & 44 & $a, b$ & -0.01 & 0.17 & 44 & $\mathrm{a}$ \\
\hline No treatment \& live birth & 0.11 & 0.18 & 69 & & 0.11 & 0.22 & 69 & $c, d, e, f$ & 0.00 & 0.20 & 69 & $\mathrm{~b}$ \\
\hline Treatment wl only \& 'no live birth & 0.42 & 0.37 & 62 & $\mathrm{a}, \mathrm{b}$ & 0.42 & 0.36 & 62 & $\mathrm{a}, \mathrm{c}$ & 0.01 & 0.23 & 62 & c \\
\hline Treatment wl only \& live birth & 0.55 & 0.39 & 31 & $\mathrm{a}, \mathrm{c}, \mathrm{d}$ & 0.47 & 0.40 & 31 & $b, d$ & -0.08 & 0.25 & 31 & $d$ \\
\hline Treatment w2 only \& no live birth & 0.24 & 0.31 & 24 & c & 0.33 & 0.30 & 24 & & 0.10 & 0.45 & 24 & \\
\hline Treatment w2 only \& live birth & 0.15 & 0.14 & 5 & & 0.30 & 0.25 & 5 & & 0.15 & 0.22 & 5 & \\
\hline Treatment $w 1 w 2$ \& no live birth & 0.16 & 0.22 & 19 & $b, d$ & 0.41 & 0.37 & 19 & e & 0.26 & 0.43 & 19 & $a, b, c, d$ \\
\hline Treatment $w 1 w 2$ \& live birth & 0.38 & 0.38 & 12 & & 0.46 & 0.41 & 12 & $f$ & 0.08 & 0.22 & 12 & \\
\hline Total & 0.28 & 0.34 & 266 & & 0.31 & 0.34 & 266 & & 0.03 & 0.27 & 266 & \\
\hline
\end{tabular}

Test for differences in means: ANOVA with Tukey's honest significant difference test for differences between specific means.

Treatment is measured as having had at least tests for infertility. All women wanted to have children.

For each column, means with the same letter are significantly different from each other.

ence of members of the research team was constructed. Respondents were presented with a series of items and asked whether they felt this way frequently, occasionally, seldom, or never. The items are: I felt cheated by life; I felt that I was being punished; I felt angry at God; I felt inadequate; I felt seriously depressed about it; I felt like a failure as a woman. The scale was computed using the mean of available items, such that it ranges from 0 to 1 . Higher scores indicate greater distress. This scale has an alpha of 0.814 for this sample at Wave 1 and an alpha of 0.843 at Wave 2 .

\section{Analytical Strategy}

For this analysis, we employed a series of one-way ANOVAs using treatment group-our classification of eight treatment/live birth composite types - as the independent variable. In three separate analyses, we used as our criterion variable fertility-specific distress at Wave 1, fertility-specific distress at Wave 2, and a change score for fertility-specific distress in order to assess whether rates of change varied among individuals in the various treatment/live birth groups. Finally, we summarize our results using a $2 \times 8$ mixed ANOVA design. The within-subjects factor was time, with measurements being taken at Wave 1 and Wave 2 . The between-subjects factor was treatment group, our classification of eight treatment/ live birth composite types. Of primary interest is the interaction effect, as a significant interaction indicates that changes in fertility-specific distress between Wave 1 and Wave 2 vary according to treatment/live birth type.

\section{Results}

The results from the first one-way ANOVA show that the eight groups differ in mean fertility-specific distress at Wave
$1\left(\mathrm{~F}_{[7,258]^{\prime}}=8.971, p<.001\right)$ (See Table 2$)$. Results of the Tukey HSD post-hoc test indicate a significant difference between women who did not receive treatment and did not have a live birth $(M=0.225)$ and both those who had treatment without a live birth in Wave 1 only $(M=0.417)$, and those who received treatment in Wave 1 only and had a live birth $(M=0.548)$ (See Table 3). To put it differently, women who reported having no treatment and no live birth reported significantly lower levels of fertility-specific distress than those who received treatment-regardless of whether or not there was a birth following the treatment. Additionally, women who did not receive treatment and had a live birth $(M=0.114)$ reported significantly lower levels of fertility-specific distress than those who had treatment either with or without a live birth at Wave 1 only $(M=0.417$ and 0.548 , respectively). Those who received treatment at Wave 1 , whether they had a child afterward or not, had significantly higher levels of fertility-specific distress than those who received treatment without a subsequent live birth in Wave 1 and Wave $2(M=0.158)$. Furthermore, women who received treatment at Wave 1 only and had a birth $(M=0.548)$ had significantly higher levels of distress than those who received treatment only at Wave 2 but did not have a birth $(M=0.238)$.

Fertility-specific distress was measured in the second wave of data collection for the 266 women who had previously met the criteria for an episode of infertility and who were still experiencing issues related to infertility at Wave 2 . The results of the one-way ANOVA at Wave 2 also reveal a significant main effect for fertility-specific distress $\left(\mathrm{F}_{[7,297]},=7.188, p<.001\right)$ (See Table 2). As before, the Tukey HSD post-hoc test indicate that women who did not receive treatment and did not have a live birth $(M=0.220)$ had significantly lower levels of fertility-specific distress than those who had treatment only in Wave 1 $(M=0.422)$ and did not have a live birth and those who received treatment only in Wave 1 and who had a live birth

Table 3. Fertility-specific distress by treatment among 266 infertile women.

\begin{tabular}{|c|c|c|c|c|c|c|}
\hline & Sum of Squares & $\mathrm{df}$ & Mean Square & $\mathrm{F}$ & & \\
\hline Fertility-specific distress at Wave I & 5.969 & 7 & 0.853 & 8.971 & $* * *$ & \\
\hline Fertility-specific distress at Wave 2 & 5.103 & 7 & 0.729 & 7.188 & $* * *$ & \\
\hline \multirow[t]{2}{*}{ Change in fertility-specific distress } & 1.663 & 7 & 0.238 & 3.466 & $* * *$ & \\
\hline & Type III Sum of Squares & $d f$ & Mean Square & $\mathrm{F}$ & & Partial Eta Squared \\
\hline Ferility-specific distress & 0.272 & I & 0.272 & 7.95 & $* *$ & 0.03 \\
\hline Time $*$ treatment group & 0.832 & 7 & 0.119 & 3.466 & $* * *$ & 0.086 \\
\hline Error (treatment group) & 41.845 & 258 & 0.162 & & & \\
\hline
\end{tabular}

$* p<.05 ; * * p<.01 ; * * * p<.001$ 


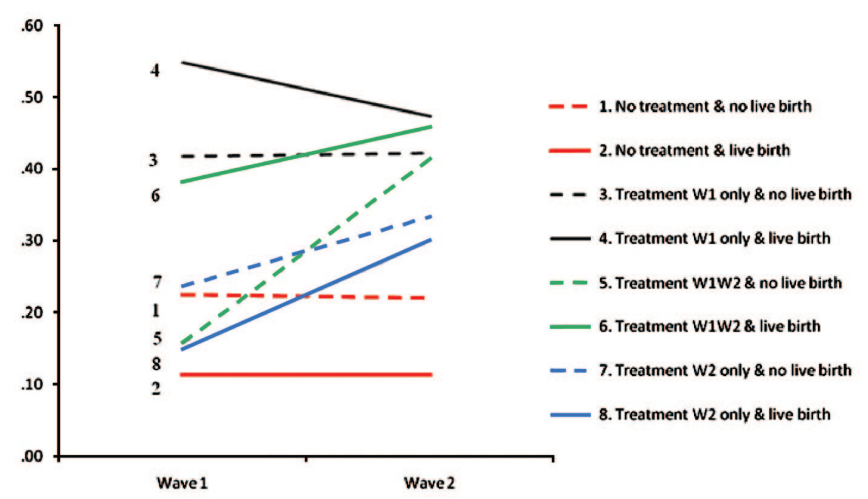

Figure I. Average FSD by wave and treatment/birth outcome.

$(M=0.473)$. Additionally, women who did not receive treatment and had a live birth $(M=0.114)$ had significantly lower levels of fertility-specific distress than those who had treatment at Wave 1 and did or did not have a live birth $(M=0.422$ and 0.473 , respectively) and those who had treatment at both waves, with or without having a live birth $(M=0.414$ and 0.458 , respectively) (See Table 2).

Next we examined differences in within-person change in fertility-specific distress between waves, by groups. The oneway ANOVA comparing group differences in average change in fertility-specific distress between waves also showed differences by treatment and outcome categories. The main effect for fertility-specific distress change scores was significant $\left(\mathrm{F}_{[7,258]^{\prime}}=3.466\right)$. The groups with no treatment or treatment only in wave 1 had either no change in fertility-specific distress, or for those who had a live birth, a decline in fertilityspecific distress. Those who hadtreatment in both waves or only in Wave 2 had increases in fertility-specific distress between waves. Those who had treatment only at Wave 2 and who had no live birth had the largest increase in fertility-specific distress scores between waves $(M=0.256)$; this group had a larger increase in fertility-specific distress scores than any of the groups with no treatment or treatment only at Wave 1.

Figure 1 illustrates changes in average fertility-specific distress scores at Waves 1 and 2 for the eight groups that we analyzed, with lines connecting the values for each group in each wave. Overall fertility-specific distress increased only for women who had treatment at Wave 2 (groups $5-8$ ), whether or not they had treatment at Wave 1 and whether or not they had a live birth (broken lines indicate no live birth). This pattern suggests that treatment is associated with fertility-specific distress. The groups that did not have treatment in Wave 2, even if they had treatment by Wave 1 and whether or not they had a live birth; all had no change or a decline in fertility-specific distress by the second wave (groups 1-4).

Finally, we conducted a $2 \times 8$ mixed ANOVA to determine if fertility-specific distress levels varied significantly over time or by treatment or live birth status among the 266 women meeting the criteria for infertility at both waves. Overall fertility-specific distress scores were significantly higher at Wave 2 than at Wave $1\left(\mathrm{~F}_{[1,258]^{\prime}}=7.95, p<.01\right)$, and the differences among the eight groups were also significant $\left(\mathrm{F}_{[7,258]^{\prime}}=9.020\right.$, $p<.001)$. The amount of change in fertility-specific distress scores depends upon treatment group, indicating an interaction effect between time and treatment status $\left(\mathrm{F}_{[7,258]^{\prime}}=3.466\right.$, $p<.001)$.

Figure 2 shows the average within-person change in fertility-specific distress scores between waves for each of the eight groups in the analysis. The first four groups (1-4) all involve either no treatment or treatment only at wave 1 . As with the pat-

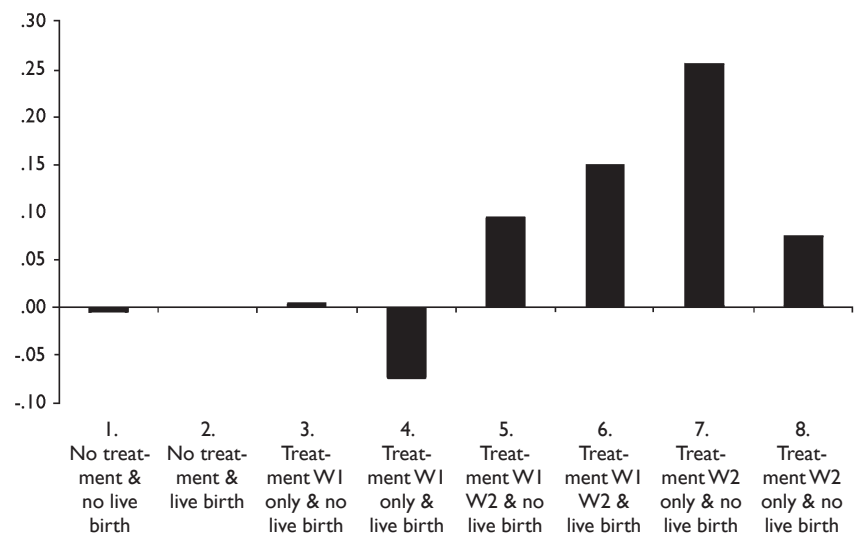

Figure 2. Wave 2 FSD-Wave I FSD within-person average change.

tern in Figure 1, this figure shows no change or a decline in fertility-specific distress between waves for the first four groups. The second four groups (5-8) all had treatment at Wave 2, and all showed an average increase in fertility-specific distress between waves. The increase was largest for those who sought treatment only at Wave 2 and who had not had a live birth.

\section{Discussion}

Hypothesis 1 predicted that women who received treatment at Wave 1 or Wave 2 would report higher levels of fertility-specific distress than women who had not received treatment. This hypothesis is partially confirmed. At Wave 1, infertile women who did not receive treatment and who had no live birth reported lower distress levels than women who received treatment at Wave 1 only, regardless of whether their infertility episode was followed by a live birth. At Wave 2, women who received no treatment had significantly lower fertility-specific distress than women who were treated at Wave 1 or at Waves 1 and 2, regardless of whether there was a subsequent live birth. Furthermore, fertility-specific distress did not increase over time among infertile women who did not receive treatment. The increase in fertility-specific distress was significantly higher for women who received treatment at Wave 2 that was not followed by a live birth than for women who received no treatment or for women who received treatment at Wave 1 only. This suggests that infertility treatment is associated with levels of distress higher than those associated with the experience of infertility in and of itself, and confirms research showing that infertility treatment is a stressful experience (Chiba et al., 1997; Daniluk, 2001; Redshaw et al., 2007). This study is the first we know of to compare fertility-specific distress among those who seek treatment to fertility-specific distress among those who do not. Our results differ from those of King (2003) who found that treatment did not have an influence on severe anxiety disorders among infertile women, but King did not have a measure of fertility-specific distress available to her.

Hypothesis 2 predicted that women who report having received treatment at both Wave 1 and Wave 2 would report higher levels of fertility-specific distress than women who have received treatment at Wave 2 only. This hypothesis received little confirmation. At Wave 2, women who reported treatment at Wave 1 and Wave 2 showed higher levels of fertility-specific distress than infertile women who did not receive treatment, but we did not find a significant difference in distress levels between other groups of women who received treatment at Wave 2 and women who did not receive treatment. Rather, it is women who received treatment at Wave 1 only who reported higher levels of distress at Wave 2. Per- 
haps women who are currently pursuing treatment or who have pursued treatment in the recent past are still hopeful that treatment will result in a live birth and are therefore less distressed. The finding that women who received treatment at Wave 1 had higher fertility-specific distress than those who received treatment at Wave 2 appears to conflict with research showing that people adjust to infertility over time (Peterson et al., 2009; Verhaak et al., 2001), but it must be remembered that our follow-up interview took place only three years after the initial interview and that it may require more time than this for levels of fertility-specific distress to diminish.

Hypothesis 3 predicted that women with live births subsequent to infertility report lower levels of distress than women who have not had a live birth. There is evidence that having a baby or not makes a difference. The group with the highest increase in fertility-specific distress was the group that was in treatment for both waves and still did not have a baby. The change for this group was significantly higher than the change in fertility-specific distress for the groups with no treatment and the groups with treatment at only Wave 1 . This is not surprising and confirms research showing that the infertile who do not eventually have a live birth are more distressed than those who do (Johansson et al., 2010; McQuillan et al., 2003; Mindes et al., 2003; Verhaak et al., 2001). A unique finding of this study is that the effect of a live birth on distress varies with treatment patterns and that fertility-specific distress increases the most among those women who have had treatment without having a live birth, yet treatment for infertility is related to distress even among women who have had a live birth.

Overall, we found that treatment was associated with fertility-specific distress beyond the effect of infertility alone, although there are some inconsistencies and nuances. Our findings suggest that counseling for infertility should include attention to the treatment process as well as coping with not having a desired child. Professionals responsible for the delivery of infertility services should consider whether there are ways to reduce the stress of infertility treatment. Counselors should try to prepare their infertile clients for the stresses of infertility treatment as well as the stress of not having a desired child.

This study was based on longitudinal analysis, but that alone did not eliminate problems with identifying causal links. Our analysis suggests that seeking treatment itself is associated with an increase in distress, but we are not able to rule out the possibility that women who experienced an increase in distress from infertility then sought treatment to help them have a child. Although this study did use longitudinal data, a major shortcoming of our work is that we had only two data points available to us. More waves of data would have allowed for a more nuanced analysis of fertility-specific distress trajectories and their relationship to treatment and treatment outcome.

Another shortcoming of this study is that power problems prevented us from looking at couples. Research has demonstrated that couple influences are important in shaping responses to infertility, but due to limited number of partners in this particular sample, we were not able to study the influence of partners on fertility-specific distress. The overall National Survey of Fertility Barriers sample, however, is sufficient to allow us to conduct other studies that look at the couple, rather than the individual, as the unit of analysis (Johnson \& Johnson, 2009). In addition, the small sample size and many analytical groups made additional control variables difficult to include. It is possible that including overall duration of infertility and overall duration of treatment would add more nuance to the results. The risk of results being confounded by uncontrolled variables is minimized, however, by the fact that our mixed ANOVA design incorporated within-person varia- tion. Thus all unmeasured variables were essentially held constant within each individual. Because it is based on a random sample of U.S. women at two points in time that allows comparisons between women who did and did not seek treatment and who did and did not have children, this study offers a unique contribution to understanding infertility. Demonstrating that infertility treatment is associated with fertility-specific distress in addition to infertility alone answers a question that infertility researchers have sought to answer for many years (Greil, 1997).

Acknowledgments - This research was supported by grant R01-HD044144 "Infertility: Pathways and Psychosocial Outcomes" funded by the Eunice Kennedy Shriver National Institute of Child Health and Human Development. An earlier version of this manuscript was presented at the 2011annual meeting of the Eastern Sociological Society, Philadelphia, PA.

\section{References}

Abbey et al., 1991 - A. Abbey, F. M. Andrews, and L. J. Halman, Gender's role in responses to infertility, Journal of Social and Clinical Psychology 15 (1991), pp. 295-316.

Anderson et al., 2003 • K. M. Anderson, M. Sharpe, A. Rattray, and D. S. Irvine, Distress and concerns in couples referred to a specialist infertility clinic, Journal of Psychosomatic Research 54 (2003), pp. 353-355.

Becker, $2000 \cdot \mathrm{G}$. Becker, The elusive embryo: How women and men approach new reproductive technologies, University of California Press, Berkeley (2000).

Becker et al., 2005 • G. Becker, M. Castrillo, R. Jackson, and R. D. Nachtigall, Infertility among low-income Latinos, Fertility and Sterility 85 (2005), pp. $882-887$.

Berg, 1994 - B. J. Berg, A researcher's guide to investigating the psychological sequelae of infertility: Methodological considerations, Journal of Psychosomatic Obstetrics and Gynecology 15 (1994), pp. 147-156.

Berg and Wilson, 1990 - B. J. Berg and J. F. Wilson, Psychiatric morbidity in the infertile population: A reconceptualization, Fertility and Sterility 53 (1990), pp. 654-661.

Bevilacqua et al., 2000 - K. Bevilacqua, D. Barad, J. Youchah, and B. Witt, Is affect associated with infertility treatment outcome?, Fertility and Sterility 73 (2000), pp. 648-649.

Boivin and Schmidt, 2005 • J. Boivin and L. Schmidt, Infertility-related stress in men and women predicts treatment outcome 1 year later, Fertility and Sterility 83 (2005), pp. 1745-1752.

Chandra et al., 2005 - A. Chandra, G. Martinez, W. D. Mosher, J. C. Abma, and J. Jones, Fertility, family planning, and reproductive health of U. S. Women: Data from the 2002 national survey of family growth, Series 23, number 15, National Center for Health Statistics, Hyattsville, MD (2005).

Chiba et al., 1997 • H. Chiba, E. Mori, Y. Morioka, M. Kashiwakura, T. Nadaoka, H. Saito, and M. Hiroi, Stress of female infertility: relation to length of treatment, Gynecologic and Obstetric Investigation 43 (1997), pp. 171-177.

Culley et al., 2006 - L. Culley, N. Hudson, F. L. Rapport, S. Katbamna, and M. R. D. Johnson, British South Asian communities and fertility services, Human Fertility 9 (2006), pp. 37-45.

Daniluk, 2001 - J. C. Daniluk, Reconstructing their lives: A longitudinal, qualitative analysis of the transition to biological childlessness for infertile couples, Journal of Counseling \& Development 79 (2001), pp. 439-449.

Edelmann and Connolly, 1998 • R. J. Edelmann and K. J. Connolly, Psychological state and psychological strain in relation to infertility, Journal of Community \& Applied Social Psychology 8 (1998), pp. 303-311.

Edelmann and Connolly, 2000 - R. J. Edelmann and K. J. Connolly, Gender differences in response to infertility and infertility investigations: Real or illusory, British Journal of Health Psychology 5 (2000), pp. 365-375.

Eugster and Vingerhoets, 1999 • A. Eugster and J. J. M. Vingerhoets, Psychological aspects of in vitro fertilization: A review, Social Science $\mathcal{E}$ Medicine 48 (1999), pp. 575-589.

Fido and Zahid, 2004 - A. Fido and M. A. Zahid, Coping with infertility among Kuwaiti women: Cultural perspectives, International Journal of Social Psychiatry 50 (2004), pp. 294-300.

Greil, 1991 - A. L. Greil, Not yet pregnant: Infertile couples in contemporary America, Rutgers University Press, New Brunswick, NJ (1991)

Greil, 1997 - A. L. Greil, Infertility and psychological distress: A critical review of the literature, Social Science E Medicine 45 (1997), pp. 1679-1704.

Greil and McQuillan, 2004 • A. L. Greil and J. McQuillan, Help-seeking patterns among subfecund women, Journal of Reproductive and Infant Psychology 22 (2004), pp. 305-319.

Greil et al., 2010 - A. L. Greil, K. Slauson-Blevins, and J. McQuillan, The experience of infertility: A review of recent literature, Sociology of Health and 
Illness 32 (2010), pp. 140-162.

Henning and Strauss, 2002 - K. Henning and B. Strauss, Psychological and psychosomatic aspects of involuntary childlessness: State of research at the end of the 1990's, Hogrefe and Huber, Ashland, OH (2002).

Hjelmstedt et al., 1999 - A. Hjelmstedt, L. Andersson, A. Skoog-Svanberg, T. Bergh, J. Boivin, and A. Collins, Gender differences in psychological reactions to infertility among couples seeking IVF- and ICSI-treatment, Acta Obstetrica Gynecologica Scandinavia 78 (1999), pp. 42-48.

Hjelmstedt et al., 2004 - A. Hjelmstedt, A. M. Widström, H. Wramsby, and A. Collins, Emotional adaptation following successful in vitro fertilization, Fertility and Sterility 81 (2004), pp. 1254-1264.

Holter et al., $2006 \bullet$ H. Holter, L. Anderheim, C. Bergh, and A. Moller, First IVF treatment-short-term impact on psychological well-being and the marital relationship, Human Reproduction 21 (2006), pp. 3295-3302.

Jacob et al., 2007 - M. C. Jacob, J. McQuillan, and A. L. Greil, Psychological distress by type of fertility barrier, Human Reproduction 22 (2007), pp. $885-894$

Johansson et al., 2010 - M. Johansson, A. Adolfsson, M. Berg, Francis, L. Hogström, and P. O. Janson et al., Gender perspective on quality of life, comparisons between groups 4-5. 5 years after unsuccessful or successful IVF treatment, Acta Obstetrica Gynecologica Scandinavia 89 (2010), pp. 683-691.

Johansson et al., 2009 - M. Johansson, A. Adolfsson, M. Berg, Francis, L. Hogström, and P. O. Janson et al., Quality of life for couples 4-5. 5 years after unsuccessful or successful IVF treatment, Acta Obstetrica Gynecologica Scandinavia 88 (2009), pp. 291-300.

Johnson and Johnson, 2009 • K. M. Johnson and D. R. Johnson, Partnered decisions? Infertility and help-seeking in U. S. couples, Family Relations $\mathbf{5 8}$ (2009), pp. 431-444.

Jordan and Ferguson, 2006 - C. B. Jordan and R. J. Ferguson, Infertility-related concerns in two family practice sites, Families, Systems and Health 24 (2006), pp. 28-32.

King, 2003 $・$ R. B. King, Subfecundity and anxiety in a nationally representative sample, Social Science and Medicine 56 (2003), pp. 739-751.

Klock and Greenfeld, 2000 • S. C. Klock and D. A. Greenfeld, Psychological status of in vitro fertilization patients during pregnancy: A longitudinal study, Fertility \& Sterility 73 (2000), pp. 1159-1164.

Malin et al., 2001 - M. Malin, E. Hemminki, O. Raikkonen, S. Sihvo, and M. L. Perala, What do women want? Women's experiences of infertility treatment, Social Science \& Medicine 53 (2001), pp. 123-133.

Matsubayashi et al., 2001 • H. Matsubayashi, T. Hosaka, S.-I. Izumi, T. Suzuki, and T. Makino, Emotional distress of infertile women in Japan, $\mathrm{Hu}-$ man Reproduction 16 (2001), pp. 966-969.

McCarty et al., 2006 • C. McCarty, M. House, J. Harman, and S. Richards, Effort in phone survey response rates: The effects of vendor and client-controlled factors, Field Methods 18 (2006), pp. 172-188.

McQuillan et al., 2003 • J. McQuillan, A. L. Greil, L. White, and M. C. Jacob, Frustrated fertility: Infertility and psychological distress among women, Journal of Marriage \& Family 65 (2003), pp. 1007-1018.

Mindes et al., 2003 - E. J. Mindes, K. M. Ingram, W. Kliewer, and C. A. James, Longitudinal analyses of the relationship between unsupportive social interactions and psychological adjustment among women with fertility problems, Social Science \& Medicine 56 (2003), pp. 2165-2180.

Monga et al., 2004 • M. Monga, B. Alexandrescu, S. Katz, M. Stein, and T. Ganiats, Impact of infertility on quality of life, marital adjustment, and sexual function, Urology 63 (2004), pp. 126-130.

Nasseri, 2000 - M. Nasseri, Cultural similarities in psychological reactions to infertility, Psychological Reports 86 (2000), pp. 375-379.

Newton et al., 1999 - C. H. Newton, W. S. Sharrard, and I. Glavac, The fertility problem inventory: Measuring perceived infertility-related stress, Fertility and Sterility 72 (1999), pp. 54-62.

Oddens, den Tonkelaar et al., 1999 • B. J. Oddens, I. den Tonkelaar, and H. Nieuwenhuyse, Psychosocial experiences in women facing fertility problems - A comparative survey, Human Reproduction 14 (1999), pp. 255-261.

Peronace et al., 2007 - L. A. Peronace, J. Boivin, and L. Schmidt, Patterns of suffering and social interactions in infertile men: 12 months after unsuccessful treatment, Journal of Psychosomatic Obstetrics \& Gynecology 28 (2007), pp. 105-114.

Peterson et al., 2009 • B. D. Peterson, M. Pirritano, U. Christensen, J. Boivin, J. Block, and L. Schmidt, The longitudinal impact of partner coping in couples following 5 years of unsuccessful fertility treatments, Human Reproduction 24 (2009), pp. 1656-1664.

Pinborg et al., 2009 - A. Pinborg, C. O. Hougaard, A. Nyboe Andersen, D. Molbo, and L. Schmidt, Prospective longitudinal cohort study on cumulative 5-year delivery and adoption rates among 1338 couples initiating infertility treatment, Human Reproduction 24 (2009), pp. 991-999.

Redshaw et al., 2007 • M. Redshaw, C. Hockley, and L. L. Davidson, A qualitative study of the experience of treatment for infertility among women who successfully became pregnant, Human Reproduction 22 (2007), pp. 295-304.
Rosholm et al., 2010 • R. Rosholm, R. Lund, D. Molbo, and L. Schmidt, Disclosure patterns of mode of conception among mothers and fathers5 -year follow-up of the Copenhagen Multi-centre Psychosocial Infertility (COMPI) cohort, Human Reproduction 25 (2010), pp. 2006-2017.

Sabatelli et al., 1988 • R. M. Sabatelli, R. L. Meth, and S. M. Gavazzi, Factors mediating the adjustment to involuntary childlessness, Family Relations 37 (1988), pp. 338-343.

Schmidt, 2006 • Schmidt, L. (2006). Infertility and assisted reproduction in Denmark; epidemiology and psychological consequences, Medical Dissertation. Danish Medical Bulletin, 53, 390-417.

Schmidt, 2009 • L. Schmidt, Social and psychological consequences of infertility and assisted reproduction-What are the research priorities?, $\mathrm{Hu}$ man Fertility 12 (2009), pp. 14-20.

Schmidt et al., 2005 - L. Schmidt, B. E. Holstein, U. Christensen, and J. Boivin, Communication and coping as predictors of fertility problem stress: Cohort study of 816 participants who did not achieve a delivery after 12 months of fertility treatment, Human Reproduction 20 (2005), pp. 3248-3256.

Stephen and Chandra, 2000 • E. H. Stephen and A. Chandra, Use of infertility services in the United States: 1995, Family Planning Perspectives 32 (2000), pp. 132-137.

Strauss et al., 1998 - B. Strauss, U. Hepp, G. Staeding, and L. Mettler, Psychological characteristics of infertile couples: Can they predict pregnancy and treatment persistence?, Journal of Community and Applied Social Psychology 8 (1998), pp. 289-301.

Ulbrich et al., 1990 - P. M. Ulbrich, A. T. Coyle, and M. M. Llabre, Involuntary childlessness and marital adjustment: His and hers, Journal of Sex and Marital Therapy 16 (1990), pp. 147-158.

Van Balen and Verdurmen, 1999 • F. Van Balen and J. Verdurmen, Medical anxiety and the choice for treatment: The development of an instrument to measure fear of treatment, Psychology of Health 14 (1999), pp. 927-935.

Verhaak et al., 2001 • C. M. Verhaak, J. M. J. Smeenk, A. Eugster, A. van Minnen, J. A. Kremer, and F. W. Kraaimaat, Stress and marital satisfaction among women before and after their first cycle of in vitro fertilization and intracytoplasmic sperm injection, Fertility and Sterility 76 (2001), pp. 525-531.

Verhaak, Smeenk, Evers et al., 2007a • C. M. Verhaak, J. M. J. Smeenk, A. W. M. Evers, J. A. M. Kremer, F. W. Kraaimaat, and D. D. M. Braat, Women's emotional adjustment to IVF: A systematic review of 25 years of research, Human Reproduction Update 13 (2007), pp. 27-36.

Verhaak, Smeenk, Nahuis et al., 2007b • C. M. Verhaak, J. M. J. Smeenk, M. J. Nahuis, J. A. Kremer, and D. D. Braat, Long-term psychological adjustment to IVF/ICSI treatment in women, Human Reproduction J22 (2007), pp. 305-308.

Verhaak et al., 2005 • C. M. Verhaak, J. M. J. Smeenk, A. van Minnen, J. A. M. Kremer, and F. W. Kraaimaat, A longitudinal, prospective study on emotional adjustment before, during and after consecutive fertility treatment cycles, Human Reproduction 20 (2005), pp. 2253-2260.

Volgsten et al., 2010 • H. Volgsten, A. Skoog Svanberg, and P. Olsson, Unresolved grief in women and men in Sweden three years after undergoing unsuccessful in vitro fertilization treatment, Acta Obstetrica Gynecologica Scandinavia 20 (2010), pp. 1290-1297.

White et al., 2006 - L. White, J. McQuillan, A. L. Greil, and D. R. Johnson, Infertility: Testing a helpseeking model, Social Science \& Medicine 62 (2006), pp. 1031-1041.

Wingert et al., 2005 - S. Wingert, C. D. H. Harvey, K. A. Duncan, and R. E. Berry, Assessing the needs of assisted reproductive technology users of an online bulletin board, International Journal of Consumer Studies 29 (2005), pp. 468-478.

Wirtberg et al., 2007 - I. Wirtberg, A. Moller, L. Hogström, S. E. Tronstad, and A. Lalos, Life 20 years after unsuccessful infertility treatment, Human Reproduction 22 (2007), pp. 598-604.

Wischmann et al., 2001 • T. Wischmann, H. Stammer, H. Scherg, I. Gerhard, and R. Verres, Psychosocial characteristics of infertile couples: A study by the 'Heidelberg Fertility Consultation Service', Human Reproduction 16 (2001), pp. 1753-1761.

Wright et al., 1991 - J. Wright, M. Allard, L. Lecours, and S. Sabourin, Psychosocial distress and infertility: A review of controlled research, International Journal of Fertility 34 (1991), pp. 126-142.

Yli-Kuha et al., 2010 - A. N. Yli-Kuha, M. Gissler, R. Klemetti, R. Luoto, E. Koivisto, and E. Hemminki, Psychiatric disorders leading to hospitalization before and after infertility treatments, Human Reproduction 25 (2010), pp. 2018-2023.

Zegers-Hochschild et al., 2009 • F. Zegers-Hochschild, G. D. Adamson, J. de Mouzon, O. Ishihara, R. Mansour, and K. Nygren et al., The International Committee for Monitoring assisted reproductive technology (ICMART) and the World health Organization (WHO) revised glossary on ART terminology, 2009, Human Reproduction 24 (2009), pp. 2683-2687. 